\title{
The impact of planned disruptions on rail passenger demand
}

\author{
Jeremy D. Shires ${ }^{1}$ (D) Manuel Ojeda-Cabral ${ }^{1} \cdot$ Mark Wardman $^{1,2}$
}

Published online: 5 July 2018

(C) The Author(s) 2018

\begin{abstract}
Disruptions to rail journeys are experienced by rail passengers on a daily basis throughout the world, with the impacts on passengers ranging from minimal to major. Such disruptions can be categorised as unplanned (e.g. extreme weather, vandalism, accidental damage to lines and power supplies etc.) or planned engineering-based disruptions. This paper focuses upon the latter, providing a valuable contribution to an area which is largely under researched, particularly in comparison to unplanned disruptions. Emphasis is placed upon understanding how passengers react to planned engineering-based disruptions: do they continue their journey (using the modified service); use other stations or routes that are not affected; make the journey on another day; travel to another destination; or simply not make that journey. Consideration is also given to how being aware or unaware may impact on passenger behaviour and whether disruptions of this type have any long run impacts over and above the short run. Ultimately, passenger behaviour translates into what can be substantial financial impacts for rail operators. The paper considers this, with the development of choice models based on both revealed preference (RP) and stated intentions (SI) data from a large scale face-to-face survey of rail users (7000+) and a smaller online panel of rail and non-rail users (500). These are used to estimate demand impacts resulting from planned engineering-based disruptions. Some of the key findings to emerge include: (1) Bus replacement services for disrupted rail services are inferior to rail diversions, with around three times more rail demand lost with bus replacement than with rail diversion; (2) The level of awareness prior to arriving at the station does not seem to have a large impact on the pattern of behavioural response, this may reflect the increased information available from mobile devices; (3) There is some evidence to suggest that rail travellers see planned disruptions as a 'fixed cost'; and (4) Guaranteed connections have a benefit, to the tune of around 9 min, whilst rail travellers have higher disutility from longer periods of disruption to the extent of around $22 \mathrm{~min}$.
\end{abstract}

Jeremy D. Shires

j.d.shires@its.leeds.ac.uk

Institute for Transport Studies, University of Leeds, Leeds, UK

2 SYSTRA, Paris, France 
Keywords Planned engineering disruptions $\cdot$ Rail demand $\cdot$ Awareness $\cdot$ Bus replacement $\cdot$ Rail diversions $\cdot$ Stated intentions $\cdot$ Revealed preference $\cdot$ Choice modelling

\section{Introduction}

\section{Aims}

Train services are from time to time disrupted due to essential engineering work undertaken for the purposes of maintaining and upgrading the railway infrastructure. Whilst fairly uncommon on any specific route, they are routine across the rail network.

This paper reports research which investigated the extent to which various features of such planned engineering-based disruptions impact on rail demand, both at the time of the disruption and in the longer term, providing some original insights in an important area where there are few previous studies. ${ }^{1}$

\section{The context}

When engineering blockades occur, railway operators generally still have a responsibility to convey passengers and they can meet this obligation in one of two ways:

- A bus replacement is offered. This might be for the entire journey, involving extended journey times, or for part of the journey. The latter would additionally involve one or two transfers between bus and train depending upon where in the journey the bus replacement occurs.

- Trains are diverted via another route, make additional stops or are retimed, all extending travel times, or frequencies are reduced by cancelling some departures.

Bus replacement is usually an inferior option for both travellers and operators due to the higher incremental costs for each (e.g. interchange penalty for travellers and bus hire for operators). Unfortunately, bus replacement is inevitably the most common measure.

Many engineering blockades occur overnight and the rail travelling public is not even aware of them. Others impact upon late night and early morning services when very few are travelling. The vast majority of major engineering works occur on a Sunday with some covering the entire weekend. Nonetheless, disruptions can have extended periods, such as those stemming from route electrification or major station and track improvements. There is though, a tendency to avoid engineering works in periods when the rail network is more heavily used, such as weekdays, and to concentrate efforts over public holidays when fewer routine journeys are being made.

In contrast, unplanned disruptions associated with extreme weather, vandalism, accidental damage to lines and power supplies, security issues, some forms of industrial action and indeed overrunning engineering work tend to be less common but extend over a prolonged period. Whilst inherently unpredictable, an unplanned disruption that has an

\footnotetext{
1 This is perhaps surprising given that engineering-based disruptions have been, and will continue as, an intrinsic feature of railway operations and often cause significant disruption to passengers.
} 
ongoing impact essentially has the same features as a planned disruption once travellers become aware of it. $^{2}$

There are a range of possible immediate behavioural responses to engineering-based disruptions. Those who are aware of the disruption in advance might continue with the planned rail journey, either using the modified service or else using other stations or routes that are not affected, make the journey on another day or travel to another destination. What does affect rail revenue is when rail travellers instead choose to travel by another mode or do not make the journey. Those who are unaware of the disruption can in principle exhibit each of the aforementioned immediate behavioural responses although they can be expected to be more constrained to the modified rail service and available alternative routes and stations.

It is worth noting that the responses described above relate to options faced by travellers' making non-rail journeys (Marsden et al. 2016b), for example when faced with a disruption to their travel or an activity a person must decide whether to: (1) continue with that journey/activity; (2) change their destination/activity; (3) continue with the same transport mode/route; (4) reschedule the journey activity; or (5) cancel the journey/activity. As such this paper positions itself within the general literature on disruption, not just rail.

Returning to the impact of planned engineering disruption, it is conceivable that there are also longer term demand impacts, for a number of reasons:

- Those who sample other modes or undertake other activities as a result of a disruption might indeed decide to continue with them even in the absence of disruptions.

- Experience or awareness of weekend engineering disruptions might instil a wariness that dissuades some from planning future weekend rail journeys.

- A bad or worse than expected experience during a disruption might increase the propensity to switch from rail on future disrupted journeys. This might particularly apply to those who were unaware of the planned disruptions beforehand.

- Prolonged disruptions might lead to high levels of frustration and dissatisfaction that induce a transfer from rail more generally.

- A poor experience may also be relayed to family, friends and peers, with potentially adverse influences on their likelihood to travel by rail.

Hence the longer term demand impacts might relate to specific ongoing journeys that were disrupted or to potential future rail travel more generally. Quantifying them is difficult and made more so by other background changes such as changing jobs, moving house etc.

\section{Scope, contribution and structure}

The scope of the research reported here was planned disruptions due to routine ${ }^{3}$ engineering works. It does not cover regular commuters since routine engineering works occur mostly at the weekend, commuters are hardly likely to switch out of rail in the long run in the event of anything other than major ongoing disruptions beyond the scope of this study,

\footnotetext{
2 Although of course, and as we shall see, not all travellers are aware of planned disruptions.

3 By routine, we mean restricted to a single day or possibly a few days with the possibility of recurrence over a few weeks but excluding major planned disruptions such as prolonged station closures as a result of significant redevelopments.
} 
and, at least in the British context, season ticket holders are reimbursed in the event of planned disruptions.

The passenger demand forecasting handbook (PDFH) has, since its inception in 1986, contained an incremental forecasting framework and associated demand parameters that are recommended for use in the rail industry in Great Britain (ATOC 2013). It is a unique document amongst railway administrations worldwide. It is regularly updated with a synthesis of best available evidence and since version 4 in 2002 has contained guidance for forecasting the impact of engineering work, initially informed by research reported by Steer Davies Gleave (1995) and with Steer Davies Gleave (2006) providing the most recent insights.

However, the PDFH evidence base is now a little dated and, as discussed in section "Background", has a number of limitations which the research reported here aimed to address. Furthermore, there is very little published research on the impact of planned disruptions on rail demand. ${ }^{45}$ This investigation aimed to advance understanding in this area by exploring:

- the differential effects of bus replacements and rail diversions, and in the former case the impact of the amount of connection time and whether connections are guaranteed;

- the impact of awareness of planned disruptions, which will have increased over time;

- the effects of different lengths of disruption and of ongoing disruptions;

- whether the behavioural change estimates differ between reported responses to actual past disruptions and stated intentions regarding hypothetical future disruptions;

- how behavioural responses vary by flow type, distance and journey purpose;

- differences between the immediate impact and the longer term demand consequences of planned disruptions.

The structure of the paper is as follows. Section "Background" discusses why the research reported here is important and warranted. The methodology is set out in section "Methodology", distinguishing between immediate and long run impacts, whilst section "Data collection and key characteristics" discusses the surveys and the key features of the data collected. The analysis of the immediate behavioural responses is reported in section "Immediate impacts" followed by forecasting applications in section "Forecasting immediate run effects". Section "Forecasting longer term demand impacts" deals with the longer term demand impacts with concluding remarks and recommendations provided in section "Conclusions".

\section{Background}

We here discuss three important background issues. Firstly, we set out why the demand impact of engineering-based disruptions is a significant issue. Secondly, we review previous work in the area. Finally, given both its uniqueness and its relevance for the research

\footnotetext{
${ }^{4}$ This contrasts with what is now a large and growing body of evidence that addresses unplanned disruptions to rail services in the form of travel time variability (Wardman and Batley 2014). We note that major reviews of demand evidence (TRL et al. 2004; VTPI 2016) have nothing to say about the impacts of planned disruptions.

${ }^{5}$ Note this journal paper draws upon a conference paper Shires et al. (2016a, b).
} 
Table 1 Types of engineering based rail disruptions (October 2017)

\begin{tabular}{llccccc}
\hline \multicolumn{6}{l}{ Classification of rail service disruptions } \\
\cline { 2 - 6 } & Bus replacement & Rail retimed & Rail diversion & Rail cancellation & Rail extended & Total \\
\hline Sunday $^{\mathrm{a}}$ & $42(46 \%)$ & $10(11 \%)$ & $14(16 \%)$ & $21(22 \%)$ & $5(5 \%)$ & 92 \\
Saturday $^{\mathrm{b}}$ & $28(40 \%)$ & $11(15 \%)$ & $11(15 \%)$ & $17(23 \%)$ & $5(7 \%)$ & 71 \\
Weekday $^{\mathrm{c}}$ & $24(62 \%)$ & $4(11 \%)$ & $5(14 \%)$ & $4(11 \%)$ & $1(3 \%)$ & 39 \\
\hline
\end{tabular}

${ }^{\text {a }}$ This is an average Sunday in October 2017, based upon 459 disruptions across 5 Sundays

${ }^{\mathrm{b}}$ This is an average Saturday in October 2017, based upon 284 disruptions across 4 Saturdays

${ }^{\mathrm{c}}$ This is an average weekday in October 2017, based upon 196 disruptions distributed between 16th and 20th October 2017

reported here, we appraise the currently recommended PDFH method for forecasting the demand impacts of planned disruptions.

\section{The significance}

Engineering works often imply significant disruptions to rail travellers' journeys in terms of extra in-vehicle time and uncertainty, the substitution of buses for trains and, in some cases, additional interchanges and connection time. ${ }^{6}$ Measures of the time inconvenience are calculated in Great Britain for the purposes of the Schedule 4 performance regime (RDG 2016), whereby train operators are compensated for the financial losses due to the infrastructure provider's engineering-based disruptions. We are though unaware of detailed published data representing these time inconveniences.

Where there are dense rail networks, such as in the London area, rail diversions might involve as little as 10 min extra. However, congestion in urban areas coupled with multiple detours to serve the often numerous local stations en-route means that bus replacements can double or more the equivalent end-to-end train journey times.

As for longer journeys, consider the service between London and Cardiff (Wales), normally involving a time of around $2 \mathrm{~h}$ for the 145 mile trip. Diverting via Gloucester when the Severn Tunnel is closed for maintenance results in a journey of around $2 \mathrm{~h} 45 \mathrm{~min}$. However, a bus replacement from Bristol Parkway would mean a $3 \mathrm{~h}$ journey, increasing to $3 \mathrm{~h} 45 \mathrm{~min}$ if the bus shuttled between Bristol Parkway and Newport. ${ }^{7}$

If the main line is blocked around Swindon, the rail diversion via Bath leads to around a $3 \mathrm{~h} 20$ min journey and would be longer if the blockage was between London and Reading. The incremental effects of a bus replacement would be of the order of an hour, although larger if the parallel road was not a motorway and there were more intermediate stations to serve.

In addition, disruptions are of course not always single events. In the context of the previous example, Network Rail (2017a) announced major works between Bristol Parkway

\footnotetext{
${ }^{6}$ With bus replacement, the requirement to interchange adds a 'fixed' penalty, the connection time is typically weighted twice in-vehicle time, and bus in-vehicle time is regarded to have a larger disutility than train in-vehicle time. These each add to the time inconvenience of planned disruptions served by bus replacements.

7 Note these are elapsed times and do not include 'fixed' penalties for interchanges.
} 
and Cardiff in the summer and autumn of 2017 which involved an initial 4-week closure of the line with replacement bus services followed by 9 weekends of further disruptions.

Table 1 provides an illustrative example based on the number of different engineeringbased disruptions undertaken in October 2017, as reported by the Network Rail Enquiries Future Engineering Website (Network Rail 2017b).

Sunday disruptions exceed (by around 30\%) those undertaken on a Saturday which in turn exceed (by around 80\%) the number undertaken on weekdays. The table distinguishes bus replacements, retiming of rail services and reduced frequencies through cancellations to fit with operational constraints, rail diversions, and extended journey times as a result of making more station stops to cover withdrawn or reduced services. There is a strong tendency for fewer cancellations and bus replacements during the weekday compared with weekends, which reflects the operational preference to minimise disruption to the higher volume of passengers who travel midweek. It is also worth noting that a large number of the weekday disruptions occur late at night to further minimise disruption, whereas weekend disruptions will often run throughout the day and evening.

Obtaining a national picture of the impact of engineering disruptions is difficult. However, Network Rail (2017c) do publish delay data on the causes of delays as part of their public performance measures. The figures for cancellations and significant lateness include disruptions from engineering works and in 2016/2017 stood at 3.8\% of all English Train Operating Companies' rail services. This is a substantive figure and whilst it is impossible to attribute accurately what level of cancellations and lateness is due to planned engineering disruption per se, it is likely to be a significant level.

Finally, the significance of planned disruptions is indicated by the considerable financial impact in the British context under the Schedule 4 performance regime. In 2015-2016, this amounted to $£ 316$ million compensation paid to train operators (Network Rail 2017d). To put this into context, around $£ 1.5$ billion was paid to Network Rail in 2015-2016 by train and freight operating companies in the form of fixed and variable charges to use the rail network.

\section{Previous research}

There is a long history in Great Britain, since the early 1980s, of conducting econometric analysis of sales data to determine the impact on rail demand of a wide range of variables. Moreover, the railways in Britain pioneered the use of market research methods to inform decision making. The considerable amount of econometric and market research evidence amassed since the 1970s is summarised in PDFH (ATOC 2013).

Despite the significance of planned disruptions, very little specific econometric analysis has been conducted. We are aware of studies that have examined the effects of shocks to the rail system stemming from industrial action, severe weather and flooding, landslips, and the consequences of the 2000 Hatfield rail crash (Glaister 1983; Owen and Phillips 1987; Wardman and Clark 2001; NERA 2003; Wardman et al. 2006; Wardman 2007; MVA Consultancy 2008, 2009; Nimako 2014). Nonetheless, these findings have very limited transferability to the impacts of planned disruptions.

As for econometric analysis focused specifically on planned disruptions, we are aware of just two studies. The most recent railway industry funded study (Steer Davies Gleave 2006) was not a success, largely due to difficulties establishing what disruptions had occurred, and hence limited data, coupled with confounding effects with public holidays and large amounts of random error in the demand data. Nonetheless, Wardman and Clark 
(2001) reported analysis of the impacts of the major redevelopment of Leeds station in 1999. Using four-weekly ticket sales data over 10 years and for 166 movements, they were able to obtain statistically significant effects for 19 of the 21 dummy variables specified for weekend track possessions. Whilst indicating that the method has considerable promise, the results are not transferable.

An alternative approach is behavioural analysis based on purpose collected survey data. Indeed, recent years have witnessed an emerging body of evidence into how travellers accommodate disruptions into both their travel behaviour and wider lifestyles (Shires et al. 2016a, b; Marsden et al. 2016a; Guiver 2011). However, this is not specifically related to rail or to planned disruptions.

Steer Davies Gleave (1995) was the first study to conduct detailed attitudinal and behavioural research of large delays to rail services but it was not restricted to planned disruptions. Nonetheless, it was the first to attempt to determine the long run impacts of delays, with rail travellers contacted using operators' customer relations databases indicating that $5 \%$ of future rail trips were lost as a result of large delays.

The only other directly relevant behavioural study covering planned rail disruptions of which we are aware is an unpublished report by Steer Davies Gleave (2006) funded by the rail industry. In addition to exploring factors that influenced awareness of the disruption and satisfaction with the replacement service, and the unsuccessful econometric analysis discussed above, the study investigated behavioural responses. The market research distinguished between those who were aware (53\%) and unaware (47\%) of the engineering possession and used a blend of actual responses and stated intentions. It indicated that, overall, $88 \%$ would still travel by train on the day, $6 \%$ would use a different route, $1 \%$ would travel on a different day and 5\% would change mode or not travel. A limitation though is that the unaware are not allowed to have a behavioural response other than making the journey by the modified train service. This might explain why the proportion retained by rail in the event of what is generally a significant inconvenience would seem to be unrealistically large. The longer term impact of experiencing a possession was explored, with $6 \%$ stating that they would generally travel by train less, $6 \%$ avoiding travelling on Sundays and $13 \%$ avoiding travelling during engineering works.

Steer Davies Gleave (2006, p. 55) had intended to build their forecasting recommendations around the findings of the demand analysis. As a result of the latter being unsuccessful, as discussed above, they stated that, "This has meant that our forecasting methodology has had to fall back on arguing by analogy: if passengers know about the impact on their journey before they set off, then they will behave in the same way as for a timetable change, and if they do not know they will behave in the same way as if a normal journey had been delayed to the same degree".

\section{The PDFH forecasting procedure}

PDFH's forecasting procedure is based on the 'by analogy' recommendations of the Steer Davies Gleave (2006) study. These consist of:

- using industry standard time elasticities to determine the demand effects of the disruption timetable compared to the published timetable for those who are aware;

- using station/route choice models to determine the extent of switching to other stations or routes for those who are aware;

- treating those who are unaware of the disruption as if they had been confronted with an unplanned disruption and using industry standard procedures for forecasting reliability. 
The main limitations of this forecasting procedure are:

- We might expect the additional time incurred through a bus replacement to have a different impact to additional rail journey time.

- Using 'analogous' PDFH recommendations for the added time for those who are aware is not necessarily appropriate. Rail travellers may be more 'accommodating' because they appreciate that such disruptions are needed to maintain and improve the railways.

- In a similar vein, using the 'analogous' PDFH recommendations relating to unplanned lateness for those who are unaware as an estimate of the long term behavioural response would at the very least seem to warrant empirical justification. Planned disruptions are of an order of magnitude greater than the vast majority of unplanned disruptions and, moreover, might be deemed less unacceptable.

- The PDFH recommendations relating to the demand impacts of time variations are explicitly long run. These long run effects have been estimated to sustained changes in timetabled journey times rather than one-off or rare changes due to planned disruptions.

- Those deemed to be unaware are only allowed to exhibit effects through the unreliability function yet clearly some will be able to amend their behaviour on the day.

- Longer term effects are not accommodated.

We should also point out that Transport for London's long established Business Case Development Manual (Transport for London 2017), which most probably contains the most extensive set of parameters worldwide for use in the appraisal and forecasting of transport-related policy measures and investments, has nothing to say about the demand impacts of planned disruptions.

\section{Methodology}

We here discuss the methods we adopted for the two distinct forms of behavioural response where we wished to obtain a better understanding:

- The immediate impacts of specific engineering disruptions;

- The longer run impact of experienced disruptions.

The immediate impacts are expected to be larger, most likely appreciably so, and are easier to detect than the impact on future trips as a result of the experiences of specific disruptions.

These methods, as discussed in section "Data collection and key characteristics", were implemented as part of both on-train surveys and an online panel survey. Surveys of rail travellers bring unique advantages over other methods (principally ticket sales analysis) for example: (1) greater clarity around the actual behavioural response and hence net revenue impact. Ticket sales analysis indicates a loss of a sales on an affected route but people could have bought a ticket for a different route/station/day which will not be identified in ticket sales data but is in the survey data; (2) distinctions in behavioural response due to journey purposes, something ticket sales cannot identify and which is useful for forecasting purposes; and (3) clearly specified variations in the precise features of the engineering disruption are possible in the survey approach, e.g. the extra journey time, the amount of 
connection time if the replacement was not for the entire journey, whether the connection was guaranteed etc.

\section{Immediate impacts}

We used two complementary survey based methods to establish how rail travellers respond in the short run to engineering based disruptions:

- Stated behavioural intentions (SI);

- Revealed preference (RP) in the forms of past behavioural responses.

\section{SI: Stated behavioural intentions}

The on-train survey asked what rail users would do in the event of an engineering based disruption on the day when they were travelling. Three bus replacement scenarios were offered which were characterised by:

- The extra journey time.

- The stations between which the bus replacement operated.

- The amount of connection time if the replacement was not for the entire journey.

- Whether the connection was guaranteed.

- Whether these arrangements would be in place for that day, three days or an entire week.

In addition, one rail diversion scenario was offered with an additional journey time. Permissible responses in both cases were:

- Travel on the replacement bus or diverted train.

- Use another undisrupted station(s).

- Use another undisrupted rail route.

- Travel by train on a different undisrupted day.

- Use a different means of transport, for one or both legs of the journey.

- Not make the journey at all.

The very nature of these exercises means that travellers can be treated as being in a state of awareness regarding the disruption.

The questions were customised to specific journeys for the purposes of realism. For example, we specified the stations between which the replacement bus would operate and we selected journeys where a rail diversion would be credible.

An online panel of the general public who had experienced a disruption to a non-commute journey as a result of rail engineering works, regardless of whether or not they made the journey, were asked about a specific disrupted journey in the past 12 months. Those who had been unaware of the disruption were asked a behavioural intention question relating to their immediate response:

- Suppose you had been aware of the disruption before setting out, what would you have done? 


\section{RP: Past behavioural responses}

This involves respondents being asked to recall what they actually did when confronted with engineering-based disruptions.

Those intercepted making a train journey were asked about the last time they experienced rail engineering-based disruptions for journeys other than commuting. We explicitly stated that they may or may not have chosen to travel by the revised service. Those who had experienced such a disruption were asked: how long ago it was; whether it was bus replacement or rail diversion, and if the former precisely where in the journey the bus replacement occurred; the journey time with and without the disruption; how many days the disruption covered, and the extent to which it was part of a series of ongoing disruptions; the journey purpose and frequency of making that journey; whether they were aware of the disruption prior to arriving at the station; and their behavioural response as set out above.

The same approach, relating to the last rail journey disrupted by engineering works, was adopted in the online panel survey of the general public.

The online panel survey also explored respondents' broader experiences of disruptions. Respondents were asked to consider all instances over the past 12 months where they had encountered an engineering-based disruption and to separately indicate the number of times they were:

- Aware of the disruption beforehand and still made the intended train journey.

- Unware of it beforehand and still made the intended train journey.

- Aware of the disruption and did not make the intended train journey.

- Unaware of it beforehand and did not make the intended train journey.

In all cases where they did not make the intended train journey, the alternative behaviour was identified in the same manner as for behavioural intentions.

\section{Longer run impacts}

Whilst we can ask rail travellers about the likely impacts on future behaviour of an engineering disruption, the responses could be surrounded by a large amount of uncertainty and possible protest response. There are therefore attractions in an approach based upon recollection of past actual behavioural responses.

The longer run impacts were examined solely through the online panel survey, and covered disruptions over the past 12 months. Respondents were asked how these had impacted on their subsequent rail trip making. Permissible responses were:

- It has made no difference to the use of train.

- Less likely to travel by train for those journeys where an engineering disruption had been experienced.

- No longer travel by train for those journeys where an engineering disruption had been experienced.

- Less likely to travel by train for any journey.

- No longer make any journeys by train. 


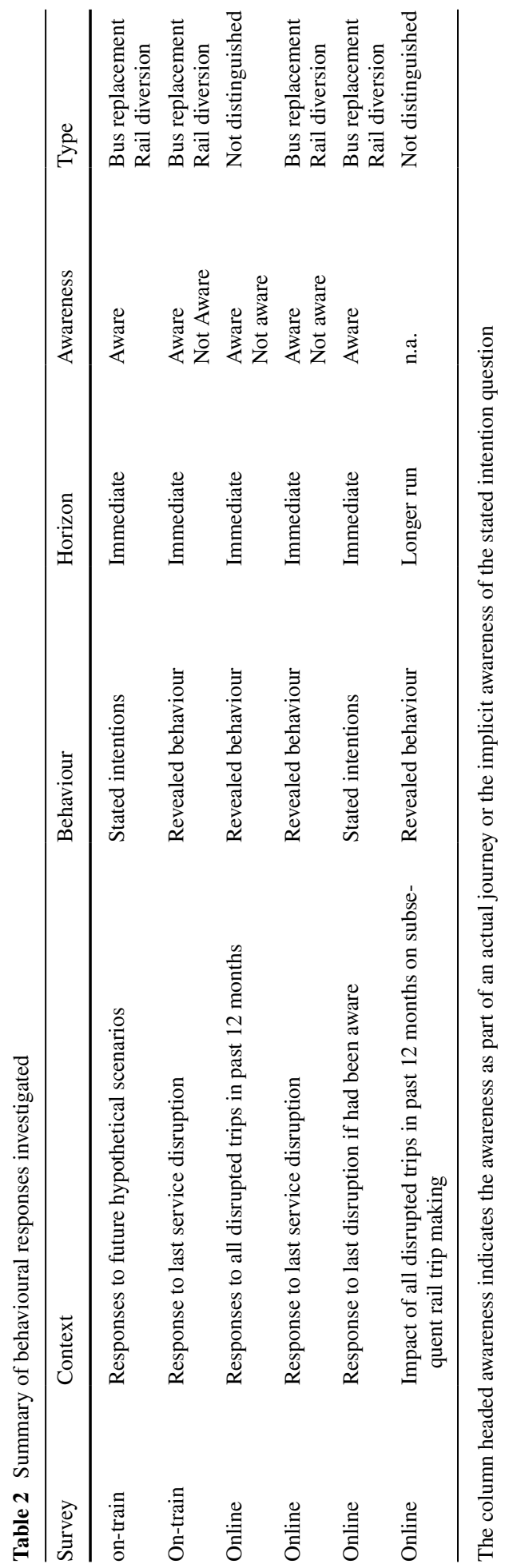




\section{Summary of methods}

Table 2 provides a summary of the various forms of behavioural response explored, the method of doing so and the type of alternative service offered.

The behavioural intentions approach has the attraction that it is experimental in nature, and hence can control the precise details of disruptions offered for consideration. It can also ask what respondents would have done if events were different, such as if they had been aware of the disruption.

The drawbacks are that it relies on respondents on average providing unbiased estimates of their collective behavioural responses yet we might expect an element of protest response. Moreover, by its very nature it places respondents in a position of perfect awareness which would not be appropriate in forecasting given some will be unaware of the disruption prior to arriving at the station.

Recalling past behaviour has the considerable attraction of being based on what people did do rather than on what they say they will do and admits unawareness. It would seem to be attractive in establishing longer run effects. Nonetheless, respondents do need to recall previous behaviour accurately, and they might still be incentivised to 'moderate' their responses in order to influence policy makers.

\section{Data collection and key characteristics}

We here describe the data collection process and summarise the key characteristics of the samples obtained.

\section{On-train surveys}

The on-train surveys provided comprehensive coverage of all the PDFH flow types which consist of the London Travelcard Area, London and the South East, Long Distance to and from London, Long Distance Non-London, Short Distance Non-London, and Airport flows. Around 12,000 survey forms were distributed, largely on trains but with some at stations where trains would be very crowded. Just over 9000 were returned, with such a high response rate facilitated by most respondents being able to complete the questionnaire during their journey.

The final sample used was nearly 7000 spread across flows as indicated in Table 7 below. We excluded those who had not completed key elements of the survey or who were out-of-scope. The latter were commuters and those whose train journeys were not covered by the questionnaire who had been inadvertently surveyed.

\section{Online surveys}

This was a panel survey of 500 respondents. After cleaning the data and removing those whose last reported disrupted journey was suspected to have been commuting, as it was made four or more times per week, we have a sample of 456 . The sample aimed to be nationally representative. 
Table 3 Gender

\begin{tabular}{llll}
\hline Gender & On-train (\%) & Online (\%) & NTS (\%) \\
\hline Male & 44 & 49 & 50 \\
Female & 56 & 51 & 50 \\
\hline
\end{tabular}

Table 4 Age group

\begin{tabular}{llll}
\hline Years & On-train $(\%)$ & Online $(\%)$ & NTS $(\%)$ \\
\hline $16-24$ & 22 & 14 & 19 \\
$25-34$ & 23 & 15 & 20 \\
$35-44$ & 16 & 16 & 20 \\
$45-59$ & 22 & 30 & 23 \\
$60+$ & 16 & 25 & 17 \\
\hline
\end{tabular}

Table 5 Main occupation

\begin{tabular}{lccc}
\hline Occupation & On-train (\%) & Online (\%) & NTS (\%) \\
\hline Employed full time & 53 & 42 & 50 \\
Employed part time & 9 & 15 & 13 \\
Retired & 12 & 18 & 13 \\
Full time education & 13 & 6 & 8 \\
Carer & 1 & 1 & 3 \\
Unemployed & 2 & 5 & 5 \\
Part time education & 1 & 1 & 0 \\
Self-employed & 8 & 8 & 8 \\
Other & 2 & 3 & 1 \\
\hline
\end{tabular}

\section{Key sample features}

We here describe the key features of the on-train and online surveys and compare them with the corresponding figures obtained from the National Travel Survey (NTS). The NTS covers the whole of England and has been undertaken annually since 1988. Data for the NTS is collected from interviews with households and asking individuals to keep a 7 day trip diary. Around 16,000 individuals in 7000 households participate. Sampling for the NTS is based upon a stratified, clustered random sample (NatCen 2015) that provides a representative account of travel in England.

Table 3 indicates that the on-train survey was made up of $44 \%$ males and it was only slightly larger at $49 \%$ in the online survey. These compare well to the NTS figure of $50 \%$.

The age distributions in Table 4 are well balanced for the on-train survey and are very much in line with the NTS evidence. The correspondence between the online and NTS distributions is weaker with what appears to be an over representation of the two oldest age group categories in the online survey. We might expect this, with an online survey, as such the discrepancy is not a major cause for concern.

Table 5 reports the distributions of the main occupations. The on-train survey figures are generally close to the NTS figures. Whilst there is a greater discrepancy for the online survey, notably in terms of a lower proportion of full time employed and a 
Table 6 Journey Purpose

\begin{tabular}{lccl}
\hline Categories & On-Train (\%) & Online (\%) & NTS (\%) \\
\hline Employers business & 16 & 6 & 18 \\
Visiting friends/relatives & 29 & 22 & 24 \\
Personal business & 5 & 13 & 9 \\
Holiday/short break & 20 & 14 & 13 \\
Educational & 5 & 4 & 10 \\
Social/recreation/shopping & 22 & 35 & 25 \\
Other & 3 & 6 & - \\
\hline
\end{tabular}

Table 7 Mean journey time by flow type (on-train survey)

\begin{tabular}{llcc}
\hline PDFH flow type & Flow & Mean time & Obs (\%) \\
\hline London TCA & Shepperton branch to London & 43 & $25(0.4 \%)$ \\
& Wimbledon to London & 26 & $84(1.3 \%)$ \\
& Shenfield and Romford to London & 44 & $80(1.2 \%)$ \\
London and South East & Oxford and North to London & 91 & $724(10.5 \%)$ \\
& Portsmouth-Haslemere to London & 120 & $468(6.8 \%)$ \\
London Long & West Yorkshire and Doncaster to London & 157 & $1988(28.9 \%)$ \\
Non-London Long & Leeds and East to Manchester and West & 128 & $1250(18.2 \%)$ \\
& Edinburgh and North to Newcastle and South & 200 & $926(13.5 \%)$ \\
Non-London Short & Skipton-Shipley to Leeds & 32 & $465(7.1 \%)$ \\
& Greenock-Paisley to Glasgow & 69 & $265(3.9 \%)$ \\
Airports & Motherwell to Glasgow & 28 & $8(0.1 \%)$ \\
\hline
\end{tabular}

This table removes about $4 \%$ of the data because of missing or unreliable journey time data. Hence the $\%$ figures sum to $96 \%$

larger proportion of retired in the online sample, again this might be expected and the differences are not a major cause for concern.

The journey purpose distributions are provided in Table 6, which for the online panel are for the last trip. We again observe a generally close degree of correspondence between the on-train and NTS samples, with visiting friends/relatives and social/ recreation/shopping trips having the largest shares. The online panel figures correspond well with those for the NTS except, as might be expected, the former contains a smaller proportion of business travellers which is compensated by a larger proportion making social/recreation/shopping trips.

Table 7 reports the mean journey times for the on-train survey and also serves the useful purpose of indicating where the surveys were conducted and the sample sizes in each. The online survey did not provide such details. The sample sizes are skewed towards the longer journeys, where it is feasible for the questionnaire to be completed during the train journey, but all flow types have at least adequate sample sizes. 


\section{Immediate impacts}

In terms of the immediate impacts of engineering based disruptions, section "Behavioural responses to engineering disruptions" discusses some key descriptive statistics for the data we have collected whilst section "Modelling of the behavioural responses" reports on more formal modelling of that data.

\section{Behavioural responses to engineering disruptions}

Table 8 provides summary behavioural responses and included in it are the three key dimensions of bus replacement versus rail diversion, whether the respondent was aware or not, and stated intentions (SI) compared to revealed preference (RP).

The categories in Table 8 are: bus or divert, which are those remaining with rail either by choosing the replacement bus or rail diversion; station and route, covering those who stated that they would/did use another undisrupted station or route; and not train, which covers the mode switch and not travel options.

Comparing the performance of bus replacement and rail diversion for given data types and levels of awareness, the ratio of people choosing rail diversion relative to bus replacement is 1.44 for the SI (rows $1 \mathrm{v} 2$ ) but averages close to 1 for the RP data (rows $3 \mathrm{v} 5,4 \mathrm{v}$ $6,9 \mathrm{v} 11,10 \mathrm{v} 12$ ). However, these figures do not tell the whole story. Turning to the traffic lost to rail, the ratio of rail diversion to bus replacement is 0.66 in the SI data but somewhat lower at 0.42 in the RP data with not a great deal of variation across the four comparisons. This is clear evidence that, as expected, the loss of rail revenue would be greater when there is a bus replacement compared to rail diversion.

We would expect the proportion choosing the bus replacement or rail diversion to fall with awareness and this is indeed the case throughout (rows $3 \mathrm{v} 4,5 \mathrm{v} 6,7 \mathrm{v} 8,9 \mathrm{v} 10,11 \mathrm{v}$ 12 ) in the RP data which has to be used to examine awareness issues. However, the impact tends to be quite modest, and certainly challenges current PDFH recommendations that those who are unaware have no behavioural response at all. Moreover, the impact of awareness on the proportion whose rail revenue would be lost is minor, moderated by increased switching to other routes and stations. On average, awareness increases the proportion choosing an alternative station by around 3\%, the proportion choosing an alternative route by around $2 \%$ and the proportion not using rail by around $5 \%$.

The largest impacts of awareness are when we bring in the SI data on what respondents would do if they had been aware and compare rows 13 and 10 and rows 14 and 12. However, the SI on what travellers would do if aware indicates a larger switch from rail than in the RP data for those aware. This might be expected since it is not uncommon that respondents provide exaggerated responses to SI questions. It is to this we now turn.

Finally, we compare the RP and SI responses. This has to be done for the actual journey where the respondent was aware of the disruption since the SI question effectively places the respondent in a position of awareness. Rows 3 and 9 indicate 74 and $66 \%$ respectively choosing the bus replacement in an actual choice context, falling to $45 \%$ in the SI situation of row 1 . On average $19.5 \%$ actually switched out of rail compared to $32 \%$ for the SI.

For the rail diversion, rows 5 and 11 indicate 69 and 67\% staying with rail in the RP context, little different to the $65 \%$ SI of Row 2. However, there is a much larger discrepancy between the proportions lost to rail which averages $9 \%$ for RP but $21 \%$ for SI. Whilst the different scenarios do not provide a controlled comparison, where only the type of data differs, 


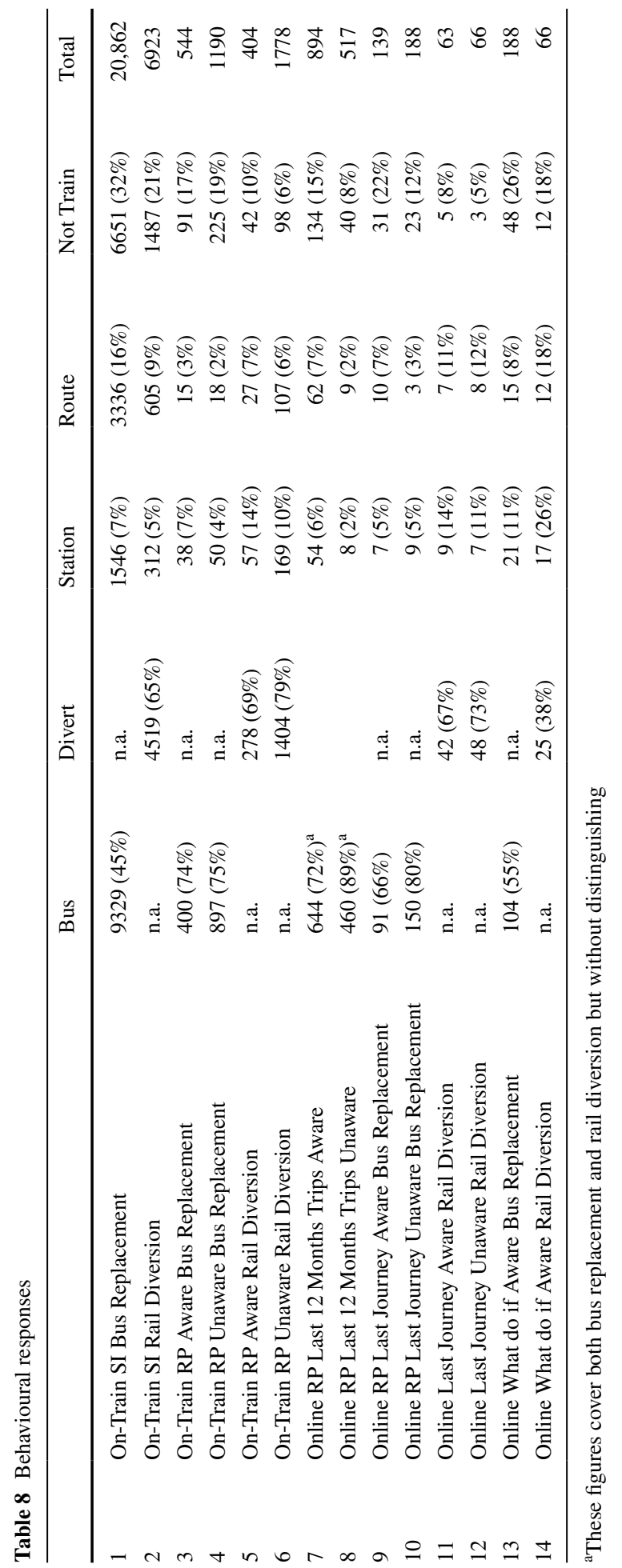


there is evidence that the SI data leads to an exaggerated response in terms of switching out of rail, with the same $12 \%$ difference for both bus replacement and rail diversion.

\section{Modelling of the behavioural responses}

Whilst tabulations are useful in giving a broad indication of how passengers might behave when faced with a planned engineering disruption, they are not able to explain in depth how behavioural responses might vary under different circumstances. To understand such responses, we estimated multinomial logit models on both the SI and RP data.

\section{Model specification}

The multinomial logit model (MNL) explains choices between the five alternatives to the modified rail option of bus replacement or rail diversion, namely another undisrupted station, another undisrupted route, a different mode, a different day of travel and not making the journey at all. The MNL was chosen above models with more complex error term structures because the latter were unable to provide meaningful results with a high degree of observable heterogeneity, mainly linked to the presence in the data of six different types of corridors (i.e. PDFH flows) and six available choices per scenario, as we shall see below. It takes the form:

$$
P_{i}=\frac{\exp ^{U_{i}}}{\sum_{j=1}^{6} \exp ^{U_{j}}}
$$

where $\mathrm{U}_{\mathrm{i}}$ denotes the utility of behavioural response $i$ and $\mathrm{P}_{\mathrm{i}}$ is the probability of an individual choosing alternative $i$. $\mathrm{U}_{\mathrm{i}}$ is related to relevant explanatory variables which for the SI data are:

- Alternative specific constants (ASCs) reflecting the inherent attractiveness of each behavioural response all else equal.

- Whether the disruption involved a rail diversion (TRAIN);

- The additional journey time (IVT) specified in the scenarios;

- The connection time (CONNECT);

- Whether the connection was guaranteed (GUAR);

- The disruption period in days (PERIOD);

- The ratings of how good the alternatives of different rail route (RATING_route), different rail station (RATING_stn), and making the journey by car or bus/coach (RATING_mode) would be on a scale of 1-10;

- Interaction effects stemming from standard PDFH flow types in particular but also journey purpose, journey length, frequency of travel, train operating company, day of travel and personal characteristics.

The 'base' utility for alternative $\mathrm{i}$ with the SI data is:

$$
\begin{aligned}
U_{i}= & A S C_{i}+\beta_{I V T i} I V T_{i}+\beta_{T i} \text { TRAIN }_{i}+\beta_{C i} \text { CONNECT }_{i} \\
& +\beta_{P i} \text { PERIOD }_{i}+\beta_{G i} \text { GUAR }_{i}+\beta_{R i} \text { RATING }_{i}
\end{aligned}
$$

The terms that describe the disrupted scenario relate only to the modified rail option whilst the rating term applies to other stations, routes and modes. The ASCs are specified for all alternatives other than the modified rail option which serves as the arbitrary base. 
The candidate explanatory variables for the RP data include the ASCs, IVT and TRAIN, along with any interaction effects, plus the impact of awareness of the disruption prior to arriving at the station (AWARE). The base utility function for any alternative with the RP data is:

$$
U_{i}=A S C_{i}+\beta_{I V T i} I V T_{i}+\beta_{T i} T_{R A I N}+\beta_{A i} A W A R E_{i}
$$

Additionally, to account for observed heterogeneity, some of these parameters were estimated separately for different segments (e.g. based on PDFH flow type), or a multiplier was added (e.g. purpose, day of week). With regard to the latter, and using the example of purpose segmentation for the IVT coefficient, we would specify instead of $\beta_{I V T i} I V T_{i}$ the following:

$$
\beta_{I V T i} *\left[D_{P U R P \_B A S E}+\left(\text { mult }_{E B} * D_{E B}\right)\right] * I V T_{i}
$$

where $D_{E B}$ is a dummy variable denoting an employer's business trip and mult $\mathrm{EB}_{\mathrm{EB}}$ is a parameter to be estimated. $D_{\text {PURP_BASE }}$ is a dummy variable denoting all other purposes. Thus if mult $_{\mathrm{EB}}$ turned out to be 1.3, then business travel would have an IVT coefficient $30 \%$ larger than for the base of leisure trips.

All the above attributes and interactions were explored in the estimated models and those that were significant or which we strongly felt merited inclusion in the final models are reported in Table 9. We estimated separate models to the RP and SI data given that, other than the ASCs, the extra journey time is the only common variable.

\section{SI results}

We discuss first the model estimated to the SI data. Separate coefficients within a model pooled across all the SI data were estimated to IVT for five flow types. These are specific to the bus replacement/rail diversion option and are all highly significant, denoting that as IVT increases then fewer will choose the bus replacement or rail diversion option. The larger ASCs for the shorter distance flows are presumably because of the greater attractiveness of alternative options for shorter trips, and hence greater sensitivity to time variations, whilst we might expect those travelling to airports to be more sensitive than those not.

Two multipliers were found to have a significant or almost significant effect on the sensitivity to time. Business travellers (mult_IVT_EB) are, on average, 16\% more sensitive to time variations whilst those travelling on a Sunday (mult_IVT_Sunday) are 7\% less sensitive. These effects seem sensible although we might have expected them to be larger in magnitude.

CONNECT is correct sign and highly significant, although with a lower coefficient than for IVT. It could be that respondents interpreted this as being part of the additional journey time and hence there is an element of it being an incremental effect. In contrast, GUAR is highly valued, equivalent to around 9 min on a long distance London journey. PERIOD has the correct sign, with an increase from 1 day to 1 week equivalent to around 22 min of extra time on a long distance London journey. Clearly, this is a large effect, and indicates that travellers are prepared to tolerate a one-off disruption but are much more averse to it being an ongoing event. Not all flow types had connection time and there was little variation in coefficients for this and guaranteed connections for those that did. The one incremental effect that was significant was a multiplier for guaranteed connections for those travelling to airports (mult_GUAR_AIRPORT) where the valuation is around $2 \frac{1 / 2}{2}$ times larger. 


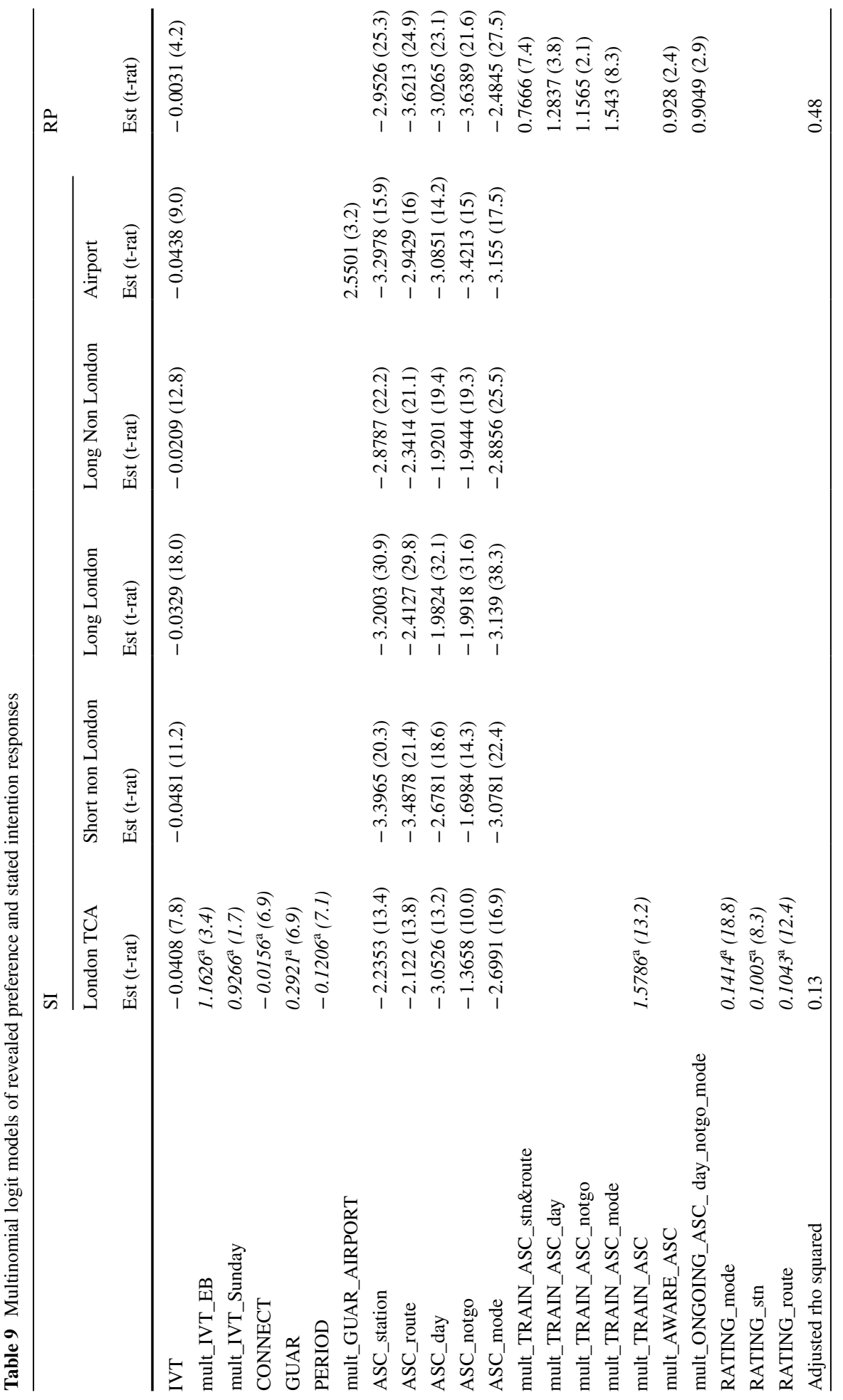




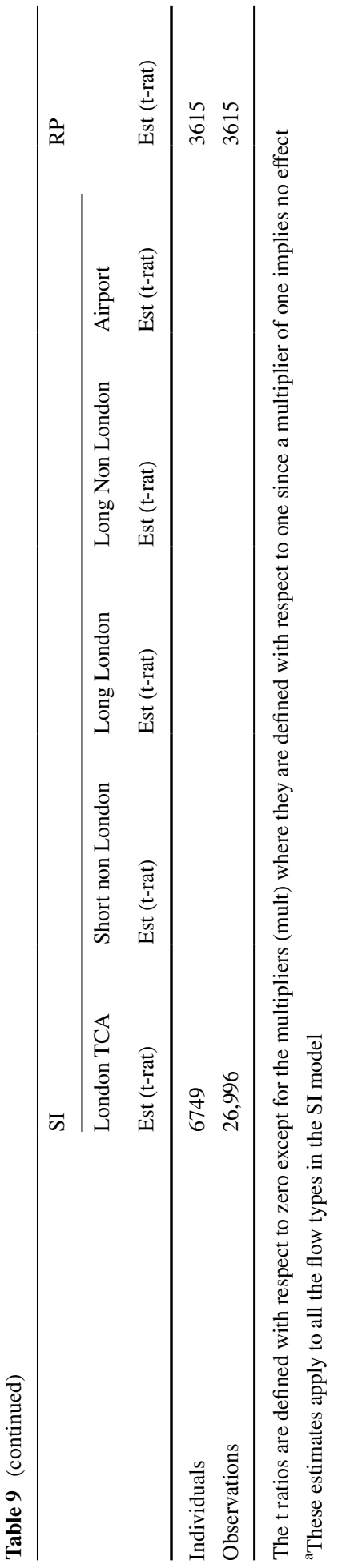


Apart from some rating variables, which we shall return to, the remaining coefficients all relate to the ASCs. These were allowed to vary across all five flow types. Given there was no clear pattern amongst the ASCs that suggested combining by alternative or flow type, we kept the 25 ASCs separate. These indicate, all else equal, the extent to which alternatives to the modified rail journey are less attractive. As expected, not travelling or travelling on a different day are particularly unattractive options for airport users whilst the reverse is the case for travelling on a different day for long distance trips. Not making the journey is indicated to be a relatively attractive option for short distance trips which are routinely made and perhaps of lesser importance.

To select some examples, the ASC for not making a trip on short distance Non London flows is equivalent to $35 \mathrm{~min}$ of extra time and the ASC for using a different mode on a long distance London flow is $95 \mathrm{~min}$, both for non-business trips not on a Sunday.

As is apparent from the results discussed in section "Behavioural responses to engineering disruptions", the option of a bus replacement is somewhat inferior to a diverted rail service. This was discerned in the estimated model. The best representation was to allow the ASCs to differ between bus replacement and rail diversion. These turned out to be very similar and hence a single multiplier term (mult_TRAIN_ASC) was estimated which applies to all ASCs. This indicates that the ASCs are 58\% larger where rail diversion is concerned, implying that all alternatives to the rail diversion would be less attractive than is the case with the bus replacement.

Finally, the rating coefficients (RATING_mode, RATING_stn and RATING_route) are based on the questions we asked as to how good it would be making the journey by car, bus/coach, another route or another station. This was on a scale from 1 (very poor) to 10 (very good) and hence the coefficients to these variables should be positive, which they turned out to be. For the switch mode option, we used the better of the ratings supplied for car and bus. Where the respondent stated that an option was 'not possible', then it was made unavailable in the choice model. The rating coefficients are quite large relative to the ASCs, with a change of five points in the mode rating being around $25 \%$ of the ASCs for mode.

\section{$R P$ results}

When compared to the SI results, the IVT $^{8}$ coefficient is of a much smaller magnitude, suggesting the presence of more noise in the choices in relation to IVT. This makes sense since some travellers would have made their RP choices with less precise (ex-ante) knowledge on the additional IVT they would actually experience and there may well have been errors in recollection. However, this explanation does not fit well with the very much better fit to the data in the RP model. Two other possible reasons as to why the RP IVT coefficient is lower are:

- The response to additional time in the SI exercise may be exaggerated, influenced by strategic bias. This is in line with the larger behavioural responses in the SI than RP data that was apparent in the discussion in section "Behavioural responses to engineering disruptions".

\footnotetext{
${ }^{8}$ The IVT coefficient in the RP model is not restricted to in-vehicle time since it will include connection time where there is interchange. This was not separately identified and the term is strictly here additional journey time.
} 
Table 10 Implied IVT elasticities for $10 \%$ journey time increase-rail diversion

\begin{tabular}{ll}
\hline Flow type and data & IVT elasticity \\
\hline Stated intention & \\
London TCA & -1.80 \\
Non London Short & -1.38 \\
London Long & -1.04 \\
Non London Long & -1.08 \\
Airport & -0.61 \\
Revealed preference & \\
Aware & -0.65 \\
Unaware & -0.52 \\
\hline
\end{tabular}

- There is a large 'fixed cost' associated with a planned disruption, such as stems from an annoyance of being disrupted, with the incremental effects of additional time being relatively unimportant.

Support for these arguments is provided by the RP model providing, as we shall see, more credible implied journey time elasticities.

There is no clear pattern in the RP ASC estimates when contrasted with the SI counterparts. However, we do observe a greater disutility associated with the option of not making the journey (ASC_notgo). This is reasonable since for SI choices a traveller might not have fully thought through and experienced the consequences of not travelling.

The RP model contains a number of statistically significant multipliers. Four of these relate to train (mult_TRAIN_ASC_stn\&route, mult_TRAIN_ASC_day, mult_TRAIN_ ASC_notgo, and mult_TRAIN_ASC_mode) and three of the four indicate, as with the SI model, that the alternatives to the modified rail option are less attractive in the case of a rail diversion (compared with the case of a bus replacement). The exception here is that different stations and routes are comparatively more attractive for the rail diversion option.

Finally, the ASCs are slightly lower for those who were aware (mult_AWARE_ASC) and also for those who stated that the disruption was part of an ongoing series of disruptions (one of a few or one of many) (mult_ONGOING_ASC_day_notgo_mode) and these imply that the attractiveness of alternatives to the modified rail option is greater where there is awareness and where the disruption period is just a one-off.

\section{Forecasting immediate run effects}

We now use the estimated models to forecast the impacts of planned disruptions on rail demand. This takes two forms. We firstly compare the implied journey time elasticities with existing evidence. Secondly, we provide illustrative demand forecasts for a range of disruption contexts, using the RP model enhanced with insights from the SI model.

\section{Implied journey time elasticities and existing evidence}

Unlike the bus replacement, the rail diversion simply involves an increase in rail IVT. We can therefore obtain IVT elasticities that can be compared with other evidence. 
The elasticity calculations are based on the models reported in Table 9 for a $10 \%^{9}$ increase in the reported journey time for each respondent in our samples. Table 10 reports the implied IVT elasticities of the SI and RP models, split by flow type for the former and whether the respondent was aware or not for the latter. As is expected, the SI elasticities are larger, almost always by an appreciable amount.

We might argue that these are not long term responses but more like instantaneous effects, although the SI elasticities are free from the lack of information that contributes to short run elasticities being less than long run. The latter might explain some of the discrepancy between the SI and RP implied elasticities.

It might also be argued that rail travellers are more accommodating of one-off or limited engineering based disruptions, since they accept that the infrastructure has to be maintained and ideally improved, whereupon the implied elasticities in Table 10 could be taken to be less than those estimated to sustained IVT variations as a result of timetable changes.

As for the empirical evidence against which these implied IVT elasticities can be compared, Wardman (2012) provides the largest ever review and meta-analysis. It is focused upon UK evidence and its findings underpin PDFH recommendations. The estimated metamodel implies IVT elasticities for static models, which form the vast majority of the rail evidence covered, ranging from -0.46 to -0.58 for trips of 10 and 25 miles respectively through to $-0.68,-0.81$ and -0.96 for trips of 50, 100 and 200 miles respectively. Explicitly short run elasticities implied by the meta-model would be $40 \%$ of these values.

This review evidence provides a reasonable degree of support for the implied RP elasticities in Table 10 but would indicate, as expected, that the SI data provides exaggerated demand responses.

\section{Illustrative forecasts of the demand impacts of planned disruptions}

When there are different sources of choice data, such as RP and SI, it is customary to estimate joint models, allowing for scale differences and indeed for any clear differences in parameter estimates across the data sets.

In this context, we have few common variables and the forms of data seem to be telling different stories. The RP data might be expected to be more reliable, and indeed the implied journey time elasticities confirm this. Pooling the data and estimating a joint model does not therefore seem justified and our preference is to use the RP model in forecasting.

However, the RP model contains fewer policy sensitive variables and we recognise that the SI model does provide more detail that should ideally be exploited. We might therefore aim to enhance the RP model with evidence from the SI model.

We rule out the connection time coefficient in the SI model since it does not seem credible, although we note that the time term in the RP model will have contained elements of connection time. Whilst the SI model provides insights into guaranteed connections and the period of disruption, these cannot be readily adopted in the RP model because whether an interchange was required was not identified, let alone whether the connection was guaranteed, and the period of the disruption is also unknown.

This leaves the SI model's rating terms that reflect the attractiveness of alternative stations, routes and modes that might be used to enhance the RP model.

\footnotetext{
9 We chose this proportion as broadly representative of the variation in IVT that underpins the econometric analysis of ticket sales data from which the vast majority of empirical evidence is obtained. The implied elasticities do not vary greatly for sensible variations around the $10 \%$ figure.
} 
The enhancement is based around allowing the ASCs of the RP model to vary with the rating of alternative travel options obtained from the SI model. Our main assumption is that the estimated RP ASCs relate to an average rating of the attractiveness of alternative options. We use the average ratings from the SI sample to input the SI rating coefficients into the RP model. Taking ASC_station as an example, we now assume the value from the RP model to be representative of an average rating of alternative stations. In the SI sample, the average rating of alternative stations is 4.82 . Average ratings of alternative routes and alternative modes are 5.19 and 5.21 respectively. To retain the original RP forecasts and have these correspond with the average ratings, the RP ASCs are adjusted as follows ${ }^{10}$ :

$$
\begin{aligned}
& \mathrm{ASC}_{\text {station }_{\text {adjusted }}}=\mathrm{ASC}_{\text {station }}-\mathrm{RATING}_{\text {_stn }} * \mathrm{E}\left(\mathrm{R}_{\text {station }}\right)
\end{aligned}
$$

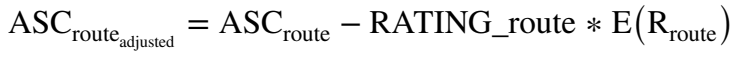

$$
\begin{aligned}
& \mathrm{ASC}_{\text {mode }_{\text {adjusted }}}=\mathrm{ASC}_{\text {mode }}-\mathrm{RATING} \_ \text {mode } * \mathrm{E}\left(\mathrm{R}_{\text {mode }}\right)
\end{aligned}
$$

where RATING_x are the SI estimates for the Rating coefficients on alternative " $x$ " and $E\left(R_{x}\right)$ represent the average rating" in the SI sample. By subtracting the term RATING_x $* E\left(\mathrm{R}_{\mathrm{x}}\right)$, the ASC_adjusted terms will equal the original ASC terms when rating $=\mathrm{E}\left(\mathrm{R}_{\mathrm{x}}\right)$. Hence, we can now use the estimated SI ratings together with the ASC terms of the RP model, such that:

$$
\mathrm{ASC}_{\mathrm{x}_{\text {forecast }}}=\mathrm{ASC}_{\mathrm{x}_{\text {adjusted }}}+\mathrm{RATING}_{-} \mathrm{x} * \mathrm{R}_{\mathrm{x}}
$$

where $\mathrm{R}_{\mathrm{x}}$ is the selected rating for the forecasts. The $\mathrm{ASC}_{\mathrm{x}_{\text {forecast }}}$ is the ASC used for forecasting purposes, and will equal the original RP ASCx when the rating of alternative " $x$ " equals $\mathrm{E}\left(\mathrm{R}_{\mathrm{x}}\right)$, i.e. the SI sample average.

Table 11 provides forecasts implied by the RP model for a range of disruption contexts, distinguishing by type of alternative service offered and awareness of disruption. Additionally, we expand these forecasts using the SI estimates of the role of availability and quality of travel alternatives (station, route or mode) on passengers' decisions.

We observe that there is not a great deal of difference between the aware and unaware respondents, which is in line with the results in Table 8. This is a challenge to existing forecasting recommendations, as we shall see, and is perhaps surprising. However, this is based on actual behavioural response to a past disruption and actual reported awareness, whereupon we would expect the responses to be reliable.

Whilst there is not a great deal of difference in the proportion who stay with rail between the bus replacement and a rail diversion, for a given amount of additional IVT, the proportion lost to rail is around three times for the bus replacement and this is not surprising.

It can be seen that there is very little variation in the proportion choosing another station or route according to how good it is perceived to be. We would expect somewhat greater proportions than say 10-20\% to choose an alternative station or route when it is deemed to be good, especially in the event of bus replacement. It seems therefore that our pragmatic attempt to handle the issue of the attractiveness of alternative stations and routes has not been successful and that the coefficients in the SI model are too low which may be because

10 An underlying assumption is that the scale of ASCs in the RP and SI models is broadly consistent. 


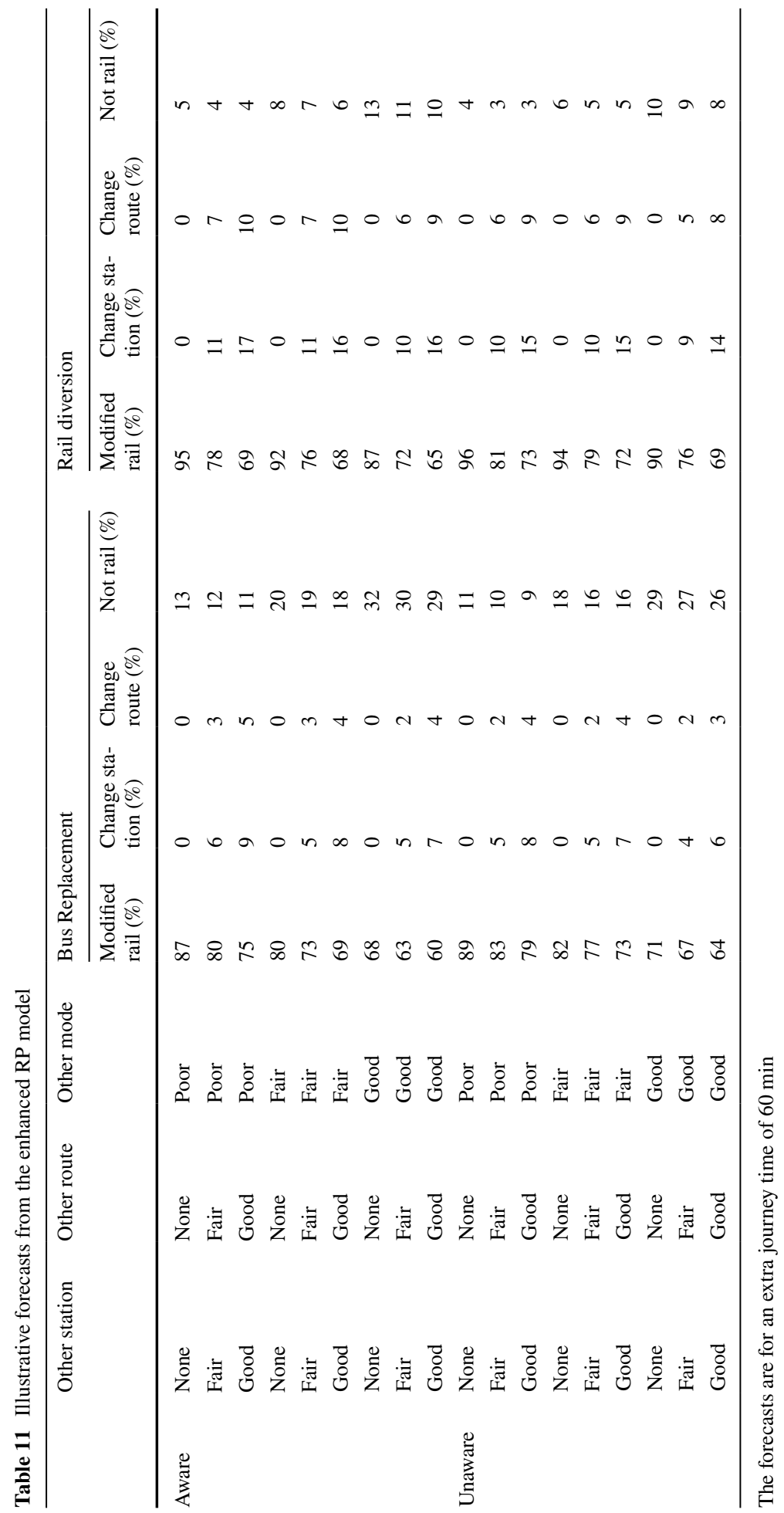


Table 12 Categorical impact on future rail use

Made no difference

Less likely to use rail where I have experienced an engineering disruption

Less likely to travel by rail for any other journey

No longer travel by rail for journeys where I have experienced an engineering disruption $4 \%$

No longer travel by rail for any other journey

Table 13 Assumptions underlying demand impacts

\begin{tabular}{lc}
\hline Trip rates & Lost trip assumptions \\
\hline Once or twice per week: 75 trips per year & Made no difference to my use of train: No effect on demand \\
About fortnightly: 26 trips per year & I am less likely to travel by rail for those journeys where I have \\
About monthly: 12 trips per year & experienced an engineering disruption: either 25\% or 50\% \\
5-10 times a year: 7.5 trips per year & demand reduction \\
2-4 times a year: 3 trips per year & I am less likely to travel by rail for any journey: either 25\% or \\
About once per year: 1 trip per year & 50\% demand reduction \\
Less than once a year: 0.5 trips per year & I no longer travel by rail for those journeys where I have expe- \\
& rienced an engineering disruption: $100 \%$ demand reduction \\
& I no longer travel by rail for any journey: 100\% demand reduc- \\
& tion \\
\hline
\end{tabular}

Table 14 Future demand impacts and the previous 12 months' trips

\begin{tabular}{lcccl}
\hline Behaviour & Indivs & Base trips & Disrupted trips & Remaining trips \\
\hline Made no difference & 274 & 4833 & & 4833 \\
No longer travel by rail for any journey & 27 & 504 & 0 & $25 \%$ Loss $=979$ \\
Less likely to travel for disrupted journeys & 76 & 1044 & 262 & $50 \%$ Loss $=913$ \\
& & & 556 & $25 \%$ loss $=417$ \\
Less likely travel any journey & 32 & $50 \%$ loss $=278$ \\
No longer travel by rail for disrupted journeys & 18 & 316 & 46 & 270 \\
Total & 427 & 7253 & & $25 \%$ loss $=6499$ \\
& & & $50 \%$ loss $=6294$ \\
\hline
\end{tabular}

of uncertainties in the ratings provided by respondents. This limits the transferability of the model in practice.

\section{Forecasting longer term demand impacts}

We have so far been concerned with what we have termed immediate impacts. We now turn to possible longer term effects of planned disruptions, the reasons for which were discussed in section "The context". The impact of planned disruptions on subsequent behaviour was addressed in the online survey by asking what had been the subsequent effect of the previous 12 months' experiences of disruptions. No distinction was made between bus replacement and rail diversion since it was not straightforward to do so. 
Table 12 reproduces the relevant categories and lists the numbers in each. The majority stated that the disruptions had made no difference to their rail trip making. As might be expected, the proportions stating a 'less likely' effect are larger than the proportions stating that they would 'no longer' make the journey by train, although the difference is slight for any other journey. The proportion who no longer travel by rail for other journeys may have been 'confounded' with those who rarely travel by rail and hence had not made a subsequent journey.

To translate the responses summarised in Table 12 into estimates of longer term impacts on rail demand, we need to account for the extent of rail trip making by each respondent and convert the categorical behavioural responses into numerical variations in rail trip rates. Table 13 sets out the assumptions we have made on both accounts.

Table 14 reports the numbers in each category of respondent along with the base number of rail trips and, where needed, the number of trip for the specific disrupted rail journey. The demand impacts are not very sensitive to the assumptions made about the loss of traffic and result in an overall long term reduction in demand of $13 \%$, assuming that less likely to travel is a $50 \%$ demand reduction, and a $10 \%$ reduction overall if the demand assumption is taken to be a $25 \%$ loss.

Some of our sample will have experienced more than one disruption, so the figures do not reflect the impacts of a single disruption. Nonetheless, most respondents had experienced just one disruption in the previous year and the results will therefore indicate an upper bound to the longer term impact of a single disruption effect.

For passengers facing a rail diversion, an intuitive relationship could be advanced for differences between short and long run impacts. A comparison with Table 8 (lines 9-12) indicates that a long term demand effect of $10 \%$ is a little higher than the short term impact from passengers' facing a rail diversion which they are aware of ( $8 \%$ loss of demand). This is also supported by Table 11, with a $7 \%$ loss for a rail diversion which passengers are aware of and the presence of 'fair' levels of alternative stations, routes and other modes. Where passengers are unaware, the short term impacts from rail diversions are, as would be expected, smaller, in the region of 5-7\%. Taken as a whole, this would suggest that when faced with disruption, passengers identify alternative behaviours which then manifests as a moderate increasing reluctance to make rail journeys in the long term.

This cannot be said for passengers faced with a bus replacement where the short term impacts are larger, sometimes considerably so (e.g. $22 \%$-line 9, Table 8), than the long term impact. Clearly, rail passengers have a strong aversion to bus replacement, as has been demonstrated throughout this paper. Why then would the long term impact reduce their reaction to bus replacement over time?

What does appear to be happening is that the long term impacts reflect the fact that planned disruptions manifest themselves in many forms (Table 1) and bus replacement appears to account for around $40 \%$ of these. We did not ask respondents what disruption they encountered when calculating long term impacts. As a result, the mix of disruptions and the different strength of responses combine to produce a long run overall impact that seems inherently sensible.

\section{Conclusions}

There is now a significant body of empirical evidence on how unplanned disruptions of a routine day-to-day nature, which generally cause modest variations in rail journey times, impact on the demand for rail travel (Wardman and Batley 2014). Indeed, the railway 
industry in Great Britain has provided recommended forecasting methods in its Passenger Demand Forecasting Handbook (PDFH) since its inception in 1986, and this seems to be unique amongst railway administrations worldwide.

Planned disruptions are the focus of this paper. They are typically associated with engineering blockades and contrast with unplanned disruption in a number of important respects: planned disruptions involve significant increases in journey times; PDFH has only provided recommendations since version 4 in 2002 and then lacking in detail; and there is a dearth of empirical evidence on how planned disruptions impact rail demand.

Planned disruptions are an inevitable feature of railway operations, stemming from routine maintenance of the infrastructure through to major investments in station upgrades and route modernisation. As such, they can have significant impacts on rail travellers and, in the British context at least, are responsible for major financial transfers between operators and the infrastructure provider.

The research reported here is one of the most extensive examinations of the demand effects of planned disruptions to rail journeys and has provided important new insights into how planned disruptions impact on rail demand in an area where there is little previous evidence.

The study used a mixture of stated intentions (SI) methods, whereby survey respondents stated how they would respond to hypothetical future disruptions, and revealed preference (RP) methods, based around how survey respondents actually reacted to experienced disruptions. It also explored possible longer term impacts using RP methods, significant because it is widely regarded that what people state that they will do in the future is unreliable because of the uncertainties involved and the incentives to biased responses and because RP is rarely used to explore such effects.

The key findings of this study are:

- As might be expected, bus replacements are an inferior means of serving engineeringbased disruptions than rail diversions. A representative figure is that three times more rail demand is lost with bus replacement than with rail diversion. Standard industry procedures in Great Britain, in the form of the recommendations of the passenger demand forecasting handbook (PDFH), need to recognise this.

- The demand responses elicited using SI are somewhat larger than for RP and the time elasticities implied by the latter accord well with evidence obtained from econometric analysis of demand changes.

- Whilst there might be a view that engineering-based disruptions will have a lower journey time elasticity than equivalent timetable changes, on the grounds that the former might be deemed more acceptable given that rail infrastructure needs to be maintained, the evidence does not support this.

- The level of awareness prior to arriving at the station does not seem to have a large impact on the pattern of behavioural response. Whilst this might be regarded to be a challenging finding, we note that over time awareness has increased (potentially related to the ability to obtain information on 'the go' via mobile devices) and that the evidence here is drawn from what rail travellers had reported that they had actually done in response to engineering-based disruptions. At the very least, our results would suggest that the PDFH recommendation that there is no behavioural response from those who are unware is inappropriate.

- There is some evidence to suggest that rail travellers see planned disruptions as a 'fixed cost' and are not particularly sensitive to the amount of additional time when making their decisions. 
- Guaranteed connections have a benefit, to the tune of around 9 min, whilst rail travellers have higher disutility from longer periods of disruption to the extent of around 22 min from moving from a daily to a weekly disruption over and above the additional journey time involved.

- The main choices seem to be between travelling by the modified service, albeit with a larger impact of bus replacement, and not travelling by the modified service.

- Credible longer term demand impacts have been obtained and this might be a function of being based on recollection of past experience rather than statement of likely future responses.

Whilst we have provided some new and important insights, further research in this area is clearly warranted.

Firstly, our attempts to address the issue of the attractiveness of other stations and routes were based on a survey based ratings, thereby avoiding the considerable resources involved in specifying in more direct quantitative terms the degree to which other stations and routes provide adequate substitutes. We have not been successful in this regard and it would seem that more detailed methods based around the relative generalised cost of different options is required.

Secondly, the issue of awareness seems critical. Our findings point to little difference between the behavioural responses of those who are aware and unaware. We have to recognise that awareness will increase over time, and hence that this will become less of an issue, but regardless of that further evidence is required that the behavioural responses of the aware and unaware are not greatly different.

Thirdly, we would contend that more monitoring work is required. Whilst our results are based on what people reported that they did, respondents might not recollect accurately their past behaviour and there remains an incentive for them to bias their responses in a strategic fashion in order to influence policy makers. Suitable monitoring of the consequences of planned disruptions beyond the scope of this study would be valuable.

Finally, the acid test is the actual demand response as recorded in the sales of rail tickets. We had intended as part of this study to undertake econometric analysis of how planned disruptions had impacted on rail demand as recorded in ticket sales, given that the analysis of such secondary data has for many years provided important insights into the key influences on rail demand. Unfortunately, the requisite demand and disruption data could not be supplied to us within the timescales of this study but its availability would open up a host of modelling opportunities.

Funding Funding was provided by Association of Train Operating Companies.

\section{Compliance with ethical standards}

Conflict of interest On behalf of all authors, the corresponding author states that there is no conflict of interest.

Open Access This article is distributed under the terms of the Creative Commons Attribution 4.0 International License (http://creativecommons.org/licenses/by/4.0/), which permits unrestricted use, distribution, and reproduction in any medium, provided you give appropriate credit to the original author(s) and the source, provide a link to the Creative Commons license, and indicate if changes were made. 


\section{References}

Association of Train Operating Companies: Passenger Demand Forecasting Handbook version 5.1. London (2013)

Glaister, S.: Some characteristics of rail commuter demand. J. Transp. Econ. Policy 17(2), 115-132 (1983)

Guiver, J.: Travel adjustments after road closure: workington. In: UTSG Conference, January, Milton Keynes (2011)

Marsden, G., Anable, J., Faulconbridge, J., Murray, L., Roby, H., Docherty, I., Chatterton, T.: Disruption: unlocking low carbon travel. Final report, EPSRC/Research Council UK Energy Programme (2016a)

Marsden, G., Anable, J., Shires, J.D., Docherty, I.: Travel behaviour response to major transport system disruptions: implications for smarter resilience planning. International Transport Forum, Discussion Paper No. 2016-09. http://www.disruptionproject.net/wp-content/uploads/2016/07/travel-resil ience-planning.pdf. Accessed on 13 Jan 2018 (2016b)

MVA Consultancy: Econometric Analysis of Long Time Series Rail Passenger Demand Aggregates. Prepared for Department for Transport (2008)

MVA Consultancy: Regional Rail Demand Elasticity. Report Prepared for Passenger Demand Forecasting Council. Association of Train Operating Companies, London (2009)

NatCen: National Travel Survey 2015: Technical Report https:/www.gov.uk/government/uploads/syste m/uploads/attachment_data/file/550854/nts-technical-report-2015.pdf. Accessed on 13 Jan 2018 (2015)

NERA: Research on long term fare elasticities: final report. Prepared for the Strategic Rail Authority (2003)

Network Rail: Major improvement works taking place in 2017 and 2018. http://www.nationalrail.co.uk/servi ce_disruptions/116354.aspx. Accessed on 20 Jul 2017 (2017a)

Network Rail: Network rail enquiries future engineering website. http://www.nationalrail.co.uk/service_ disruptions/currentAndFuture.aspx?TravelDate=23\%2F07\%2F2017\&TOC. Accessed on 20 Jul 2017 (2017b)

Network Rail: Public performance measure. https://www.networkrail.co.uk/who-we-are/how-we-work/perfo rmance/public-performance-measure/ (2017c)

Network Rail: Information and data. https://www.networkrail.co.uk/who-we-are/transparency-and-ethics/ transparency/datasets/. Accessed on $20 \mathrm{Jul} 2017$ (2017d)

Nimako, K.: The Dawlish railway line collapse. M.Sc. Transport Dissertation, University of Leeds, p. 6 (2014)

Owen, A.D., Phillips, G.D.A.: The characteristics of railway passenger demand. J. Transp. Econ. Policy 21, 231-253 (1987)

Rail Delivery Group: Response to: Office of Rail and Road PR18 Reviews of Schedules 4 and 8 of track access contracts (2016)

Shires, J.D., Marsden, G., Anable, J., Docherty, I.: Forth road bridge closure survey: analysis of commuter behaviour. Funded by Impact Acceleration Accounts (EPSRC \& ESRC) (2016a)

Shires, J.D., Ojeda-Cabral, M., Marsden, G., Wardman, M.: The impact of disruption on rail passenger demand. European Transport Conference, Barcelona (2016b)

Steer Davies Gleave: Big Delays. Report to Operational Research Unit. British Railways Board, London (1995)

Steer Davies Gleave: Demand Effects of Possessions. Prepared for the Passenger Demand Forecasting Council. ATOC, London (2006)

Transport for London: Business Case Development Manual, TfL Programme Management Office (2017)

Transport Research Laboratory, Centre for Transport Studies University College London, Transport Studies Unit University of Oxford, Institute for Transport Studies University of Leeds, Transport Studies Group University of Westminster (2004): Demand for Public Transport: A Practical Guide. TRL Report TRL593, Crowthorne, Berkshire

Victoria Transport Planning Institute: Transportation cost and benefit analysis: techniques, estimates and implications. http://www.vtpi.org/tca/ (2016)

Wardman, M.: Demand for rail travel and the effects of external factors. Transp. Res. E 42(3), 129-148 (2007)

Wardman, M.: Review and Meta-Analysis of U.K. Time Elasticities of Travel Demand. Transportation 39, 465-490 (2012)

Wardman, M., Batley, R.: Travel time reliability: a review of late time valuations, elasticities and demand impacts in the passenger rail market in great Britain. Transportation 41(5), 1041-1069 (2014)

Wardman, M., Clark, S.: Leeds 1st revenue impact. Final Report for Northern Spirit Train Operating Company and Railtrack (2001) 
Wardman, M., Dargay, J., Toner, J.P., Whelan, G.A.: Fare elasticity evidence in Scotland. Final Report to Transport Scotland (2006)

Jeremy Shires is a Senior Research Fellow and Market Research Manager at the Institute for Transport Studies (University of Leeds), with nearly 25 years of experience in transport research. His main research interests lie in transport policy, stated preference design, appraisal and forecasting within the public transport field. The majority of his work has been in the bus and rail sectors but he maintains strong interests in the fields of disabled transport provision and new technologies.

Manuel Ojeda-Cabral is a Senior Research Fellow at the Institute for Transport Studies (University of Leeds). His research is focused on the economic appraisal of public sector projects and policies and, in particular, cost-benefit analysis and the valuation of non-market goods such as time, the environment and urban realm. Most of his work falls within the remit of the transport sector and is published in world-leading journals. Manuel works closely with major public sector agencies, industry and other organizations, while regularly contributing to national and international research projects directly linked to economic policy.

Mark Wardman is Technical Director at SYSTRA and Visiting Professor at the Institute for Transport Studies, University of Leeds. Mark has been involved in transport research for over 30 years, and a particular feature has been the analysis of the demand for rail travel. He has published extensively in this area and his research has impacted significantly on the demand forecasting methods and parameters that are widely used in the railway industry in Great Britain. 